\title{
Comments on 'Strategic Maneuvering in Direct to Consumer Drug Advertising: A Study in Argumentation Theory and New Institutional Theory'
}

\author{
Bilal Amjarso
}

Published online: 11 April 2008

(C) The Author(s) 2008

In his paper, Thomas Goodnight contributes to the discussion on strategic manoeuvring within institutional argumentative exchanges starting from the idea that the obligations imposed and possibilities provided by the particular institution in which the exchange takes place define the way arguers resolve their differences of opinion. Argumentative exchanges between doctor and patient involving direct-toconsumer drug advertising are given as an example.

In this commentary I will focus on Goodnight's employment of the concept of reasonableness and show how it differs from the concept of reasonableness adopted in the pragma-dialectical theory, arguing that the latter can be instrumental in accounting more systematically for argumentation both within and among institutions.

Goodnight's basic starting point in his endeavour is that rationality comes from the institution. It is 'reducible neither to interactions which are regulated by conversational norms nor to the obligations of achieving effects on opinion through persuasive exchange.' 'What counts as reasonable thinking and valid judgment is', according to Goodnight, 'grounded in the logic of the institution.'

By taking account of the type of reasonableness advocated by Goodnight, one may say that his endeavour is not so much to show how in a pragma-dialectical sense the arguers' strategic manoeuvring within an institutional context is affected by the contingencies of the institutional situations but to show how this strategic manoeuvring is actually defined by the institutional context because it is this institutional context that determines what is reasonable and what is not. In fact, the idea for this conception of strategic manoeuvring is understandable to some extent because it is clearly based on the belief that in institutional settings arguers also have to balance their personal ambitions with the norms imposed by the institution within which the argumentation takes place. So what is there to be said against this conception?

B. Amjarso ( $\square)$

Department of Speech Communication, Argumentation Theory and Rhetoric,

University of Amsterdam, Spuistraat 134, 1012 VB Amsterdam, The Netherlands

e-mail: B.Amjarso@uva.nl 
In my view Goodnight's conception of strategic manoeuvring relies too heavily on the reasonableness of the institution. No matter how powerful and enduring a given institution may be, it would be too risky to rely solely on the institution to determine for us what is reasonable and what is not. A general and more encompassing form of rationality, such as the one advocated by the pragmadialectical theory, remains necessary. Goodnight does show awareness of this fact when he says that '[i]n cases of conflict, institutional advocates draw upon higher order principles of argument to criticize the norms of reasoning in organizations,' but this, in as far as I understand Goodnight's analysis, only applies to cases involving conflicts between different institutions and to cases where arguers come to realise that the norms of their own institutions may not be acceptable to an arguer belonging to the rival institution.

In my opinion, even within the same institution arguers might be assumed to appeal to some higher conception of reasonableness in addressing one another. Besides, the fact that arguers assume different roles within different institutions at the same time can also be a reason why the institutionally 'bounded rationality' is potentially undermined by the institution-independent rationality. Assuming that arguers rely on this higher form of rationality in their routine institutional argumentation may explain why arguers are able to move between different institutions and become good arguers within the receiving institution. In fact, for what one may call a multi-institutional agent (an agent functioning within various institutions) codes of rationality adopted within an institution may make sense and are acceptable to them only because they bear similarities to some higher form of reasonableness.

For effective argumentation within an institution, this higher form of reasonableness is necessary, yet not sufficient. I certainly don't want to claim that the institution has no hand in determining what should count as reasonable and as unreasonable for its arguing agents. What I think is the case is that the norms and goals of the institution can play a role in the way in which this higher form of reasonableness is put to work in actual cases of argumentation. In this respect, Goodnight is right to note that the institution provides the 'givens' that arguers start from in testing the acceptability of their standpoints, but the fact that arguers base their discussions on these givens should not rule out that these givens become themselves subject to critical testing.

Starting from an institution-based conception of rationality carries with it the risk of assuming a certain hierarchy in analysing institutional argumentation. Goodnight has made it clear that power is an important factor when it comes to how institutions deal with one another. As a result, an agent affiliated with a powerful institution may enjoy some privileges during an argumentative exchange with an agent not affiliated with that institution. In the case of an exchange between a provider and a client (e.g. a health specialist and a patient) it is obvious that the provider is in a powerful position vis-à-vis the client and that the latter is in need of the former's help and feedback. One, however, may be misled in thinking that it is rational for the specialist to assume the role of the persuader and for the patient to assume the role of receiver. Such view would deprive the client of any significant active role in the exchange. The analyst, therefore, need not restrict himself to the 'givens' that these agents themselves may start from but should take into account that a client is 
an equal party in the exchange who can also engage in persuasive argumentation targeted at the specialist and can, despite his lack of expertise, also subject the provider's contributions to criticism. The analyst should show how in light of a more encompassing notion of reasonableness arguers can manoeuvre strategically to achieve their goals and how this reasonableness is sometimes undermined by, for instance, the power relations that characterise the argumentative exchange at hand. Van Eemeren and Houtlosser's concept of strategic manoeuvring has given the analyst more tools for identifying ways in which arguers can exploit the givens of the institution to their own advantage (van Eemeren and Houtlosser 2005). The main thrust of their approach is that the analyst should not take the actual asymmetry between arguers for granted but he should take them into account.

This is not to say, however, that Goodnight's analysis of the way direct-toconsumer advertising in the field of pharmaceutical industry affects exchanges between doctor and patient is not extremely insightful. The analysis sheds light on the way changes in institutional discourses can affect the possibilities of strategic manoeuvring for institutional arguers and shows how the asymmetry between doctor and patient may be adjusted in favour of one arguer or another. In the case analysed by Goodnight it is the patient who benefits. The case can be considered as an example of a form of strategic manoeuvring typical of the opening stage of a critical discussion where parties exchange moves regarding the allocation of the burden of proof. What can be concluded from this particular case is not that thanks to regulatory changes it is now reasonable for the patient to impose more burden of proof on the doctor - this burden of proof is there anyway-but that these changes have, as Goodnight explains, given more room to the patient to manoeuvre strategically. In addition, the analyst should not be tempted to assume that it is necessarily unreasonable for the doctor to refuse to comply with the patient's demand that he assume the burden of proof. Within the boundaries of rationality, the burden of proof remains an issue for discussion that arguers solve intersubjectively independent of what a given institutional change may have imposed.

To conclude, both Goodnight's approach and analysis have left no doubt that argumentation theory can indeed benefit from the study of institutional discourse. In this commentary I tried to show that while the insights gained from Goodnight's approach and analysis are indispensable for students of argumentation these insights can be made even more useful if an institution-independent concept of reasonableness is given more space within this approach.

Open Access This article is distributed under the terms of the Creative Commons Attribution Noncommercial License which permits any noncommercial use, distribution, and reproduction in any medium, provided the original author(s) and source are credited.

\section{Reference}

Eemeren, F. H. van, \& Houtlosser, P. (2005). Theoretical construction and argumentative reality: An analytic model of critical discussion and conventionalised types of argumentative activity. In D. Hitchcock (Ed.), The uses of argument: Proceedings of a conference at McMaster University, 18-21 May 2005 (pp. 75-84). Hamilton, ON: Ontario Society for the Study of Argumentation. 